\title{
CONFIGURATION SELECTION AND ANALYSIS OF A SUPERSTRUCTURE SOLAR SAIL
}

\author{
Suresh $\mathrm{P}^{1}$, Aadesh Varne ${ }^{2}$, Jishnu V C ${ }^{3}$, Kushal U ${ }^{4}$, Parth Borse ${ }^{5}$ \\ ${ }^{1}$ Assistant Professor, Dept of Aeronautical Engineering, Dayananda Sagar College of Engineering. \\ 2,3,4,5 Student, Dept of Aeronautical Engineering, Dayananda Sagar College of Engineering.
}

\begin{abstract}
Solar sail propulsion is one of the most innovative spaceship propulsion system which make use of the radiation pressure in space. The continuous supply of radiation pressure means the ship has infinite propellant reserve. Theoretically, the solar sail keeps accelerating to gain high velocities due to this continuous supply of radiation pressure, therefore this system is ideal for interstellar exploration. As there are numerous developments going on this field of study, it is important to have a generalized sail design that can be used for further developments. This paper gives the configuration selection of the sail along with calculations and analysis to develop a superstructure solar sail, which is theoretically ideal for interstellar exploration and for future engineering
\end{abstract}

Keywords: Superstructure; Interstellar exploration; Solar sail

\section{Introduction}

A solar sail is a fuel-free system in which pulses are generated by exchanging pulses from reflected photons.

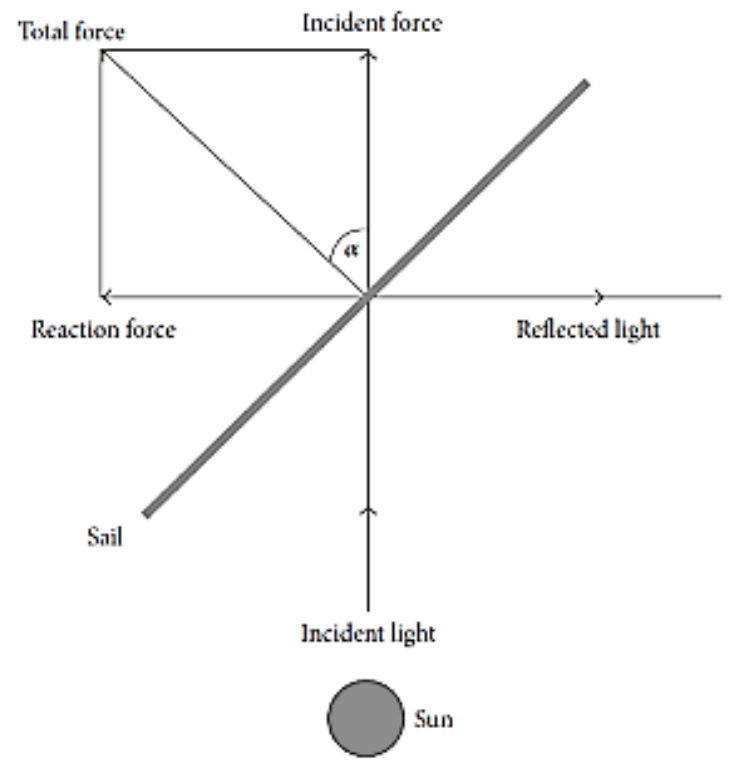

Figure 1. A sketch of the interaction of the solar photons with the sail
The continuous pressure of photons makes the thrust of the engine smaller when it travels in space. The solar sail will accelerate slowly but surely and reach very high speeds, which is useful for interstellar exploration. The solar sail is usually a lightweight, deployable spacecraft structure that uses a large area of highly reflective film. The solar pressure decreases in proportion to the square of the distance to the sun. Therefore, solar sails absorb a lot of energy when they are close to the sun. The solar radiation pressure is very low, about $6.7 \mathrm{~N} / \mathrm{GW}$, which is equivalent to $9.12 \times 10^{6} \mathrm{~N} / \mathrm{m}$ in low-Earth orbit. The performance of the solar sail is largely affected by four main factors: the sail surface. /Mass ratio; optical properties of sail film; mechanical properties of sail film; and sail geometry.

\subsection{IKAROS}

IKAROS (Interplanetary Kite-craft Accelerated by solar radiation) is an experimental spacecraft of the Aerospace Exploration Agency (JAXA). IKAROS is the first spacecraft to successfully demonstrate solar sail technology in interplanetary space. The mission involves the deployment and operation of large and thin solar sail membranes. Measure acceleration due to radiation pressure, explore various aspects of interplanetary space, such as gamma rays, solar wind, etc. The asteroid probe, which will be launched soon, will go to the asteroids Jupiter and Trojan, and bring samples of the asteroids back to Earth.

The success of the IKAROS solar sail marks the beginning of a new era of solar navigation. Unlike other spacecraft, the sails of many solar ships cannot be effectively tested on Earth due to their size. Therefore, in solar sail research, mathematical models and simulations are often used without experimental verification. Therefore, special attention should be paid to the assumptions made, because inappropriate assumptions will greatly reduce the reliability of the results. Many SRP (solar radiation pressure) performance models have been developed for solar sails, each with different assumptions and accuracy. Modeling will be an interesting area for future research. 


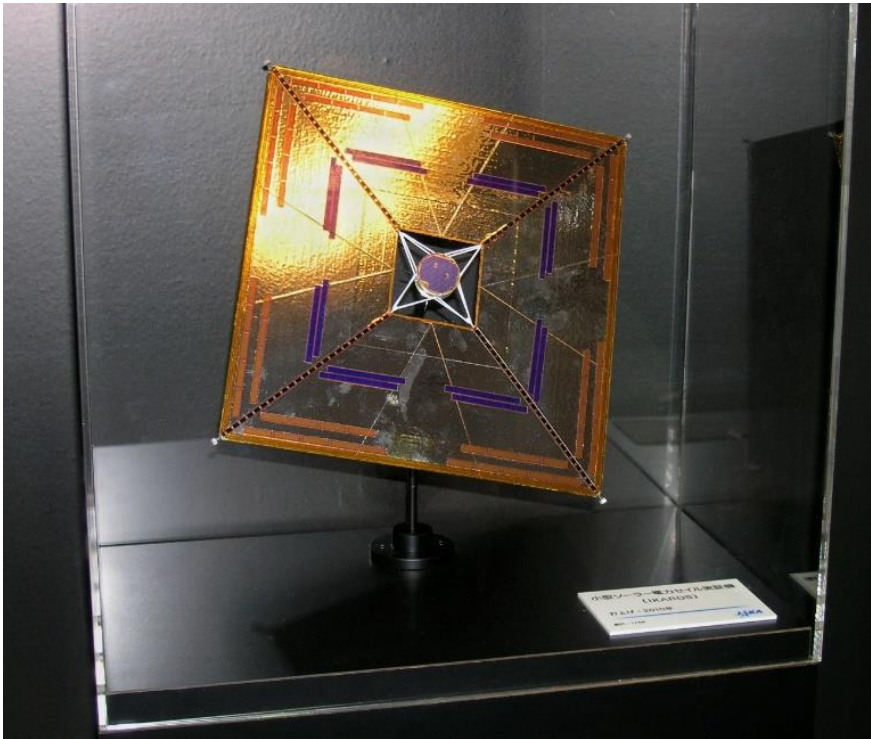

Figure 2. 1:64 scale model of the IKAROS spacecraft

\section{Methodology}

\section{SOLAR SAIL CONFIGURATION SELECTION}

\section{SAIL DESIGN CALCULATIONS}

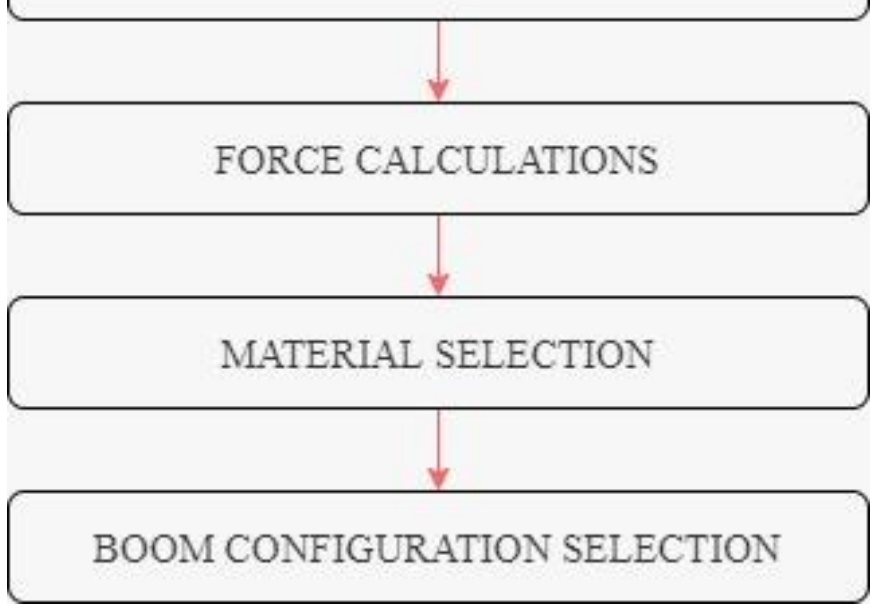

\section{Figure 3. Methodology}

First selection of the type of solar sail configuration is done, and then calculations of the sail design is done. Next Calculation of the total force on the sail based on the solar radiation pressure. The material of the sail is selected according to the requirements of the structure and the characteristics of its surroundings. Analyze various configurations, and then select a configuration that meets the design requirements.

\section{Design of sail}

\subsection{Configuration selection of sail}

There are five configurations of solar sails, four-point suspension, five-point suspension, single quadrant, continuous connection and split structure.

a

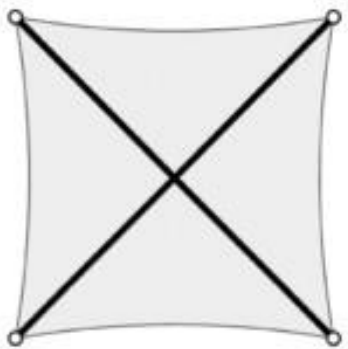

Four-point suspension.

b

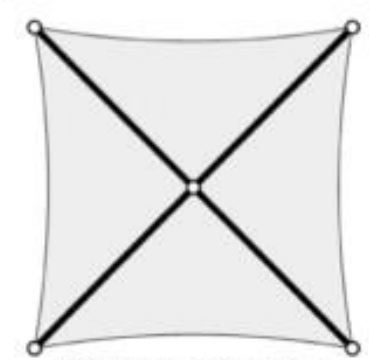

Five-point suspension.

d

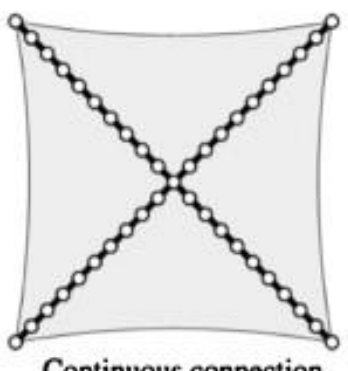

Legend:

○ sail suspension from boom

- sail surface edge

... strip borders / stress direction boom

C

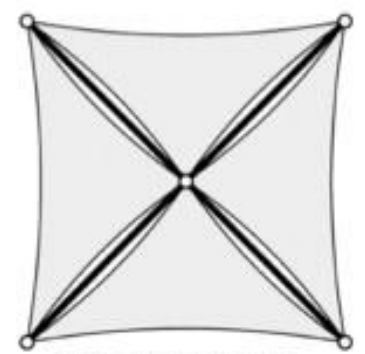

Separate quadrants.

e

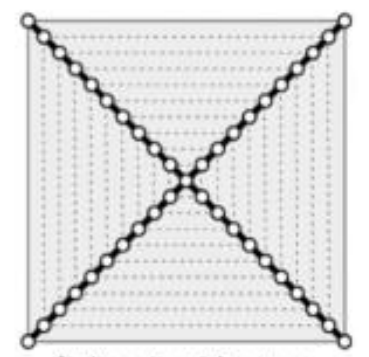

Stripped architecture.
Figure 4. Various Sail Configuration (a) Four-points suspension (b) Five-point suspension (c) Separate quadrants (d) Continuous connection (e) Stripped architecture

Stress distribution on the sail material differs in each configuration. By considering the strength required and the stress distribution the two configurations that have better characteristics are continuous connection and stripped architecture. Even though stress distribution is better in stripped architecture, we selected continuous connection taking into account the mission requirements. Continuous connection has uniform distribution of photons falling on it, easier to incorporate control mechanism.

\subsection{Sail sizing}


The dimension of the first-generation sails lies between $100 \mathrm{~m}$ to $200 \mathrm{~m}$ depending on the mission destination. Since the sail must be designed to reach the heliosphere, we have taken the dimension of the square sail to be $150 \mathrm{~m}$.

\subsection{Sail design calculation}

Catenary sag is the tension-less section of the belt that hangs down on the underside in a conveyor belt.

Catenary Sag was calculated by using the formula,

$\delta_{\mathrm{c}}=\xi \mathrm{x} \mathrm{b}_{\mathrm{m}}$

where,

$\xi$ - Normalized outboard catenary sag, $\xi<0.05$

$\mathrm{b}$ - sail length $=150 \mathrm{~m}$

The normalized outboard catenary sag is taken as 0.05 so that the reflectivity of the sail will be maximum while the load acting on the outboard sail material will be minimum.

$$
\delta_{c}=0.05 \mathrm{~m} \mathrm{x} 150 \mathrm{~m}=7.5 \mathrm{~m}
$$

The catenary sag was calculated to be $7.5 \mathrm{~m}$. The sail thickness was calculated by using solar loading formula.

Solar loading, $\sigma=\frac{\text { Mass of the solar sail }}{\text { Area of the solar sail }}$

$\sigma=\frac{\rho x V}{A}=\frac{\rho x \cdot A x t}{A} \mathrm{~kg} / \mathrm{m}$

where, ${ }^{P}$ - density of the solar sail material, $\mathrm{kg} / \mathrm{m}^{3}$

$\mathrm{V}$ - Volume of the solar sail, $\mathrm{m}^{3}$

$\mathrm{t}$ - thickness of the sail material, $\mathrm{m}$

The range of the solar loading usually lie between 0.02 $\mathrm{kg} / \mathrm{m}^{2}$ to $0.03 \mathrm{~kg} / \mathrm{m}^{2}$. We have taken ${ }^{\sigma}=0.02 \mathrm{~kg} / \mathrm{m}^{2}$ and the density of mylar is $1380 \mathrm{~kg} / \mathrm{m}^{\text {a }}$.

By substituting these in the formula,

Solar sail thickness, $\mathrm{t}=\frac{\sigma}{\rho}=14 \mathrm{x}^{10^{-6} \mathrm{~m}}$

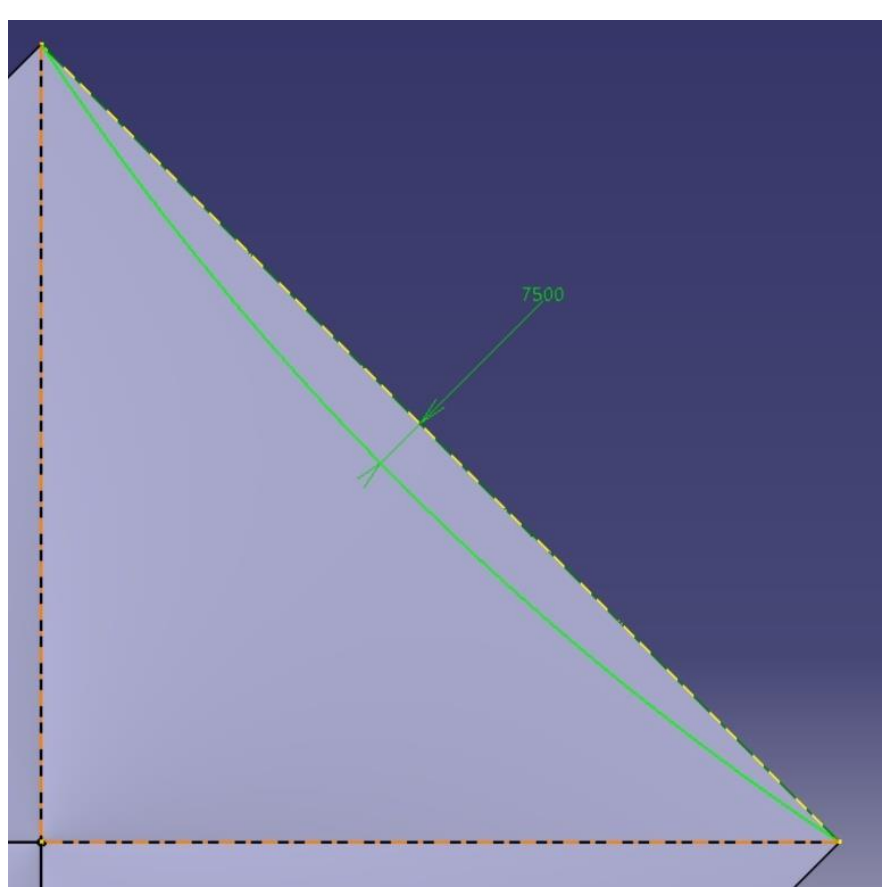

Figure 5. Catenary sag

The radius of curvature of the outboard sail is calculated using the formula,

Radius of curvature, $R_{\min }=\frac{\sigma_{\min x} t_{\min }}{P_{\max }} \mathrm{m}$

where,$\sigma_{\text {min }}$ - minimum film skin stress, $\mathrm{N} / \mathrm{m}^{2}$

$t_{\min }$ - minimum thickness of the film, $\mathrm{m}$

$P_{\max }$-maximum light pressure, $\mathrm{N} / \mathrm{m}^{2}$

We have taken $\sigma_{\min }$ to be 1 psi which is $6894.75 \mathrm{~N} / \mathrm{m}^{2}$. The maximum light pressure is calculated to be $9.01 * 10^{-6} \mathrm{~N} / \mathrm{m}^{2}$. Substituting these values,

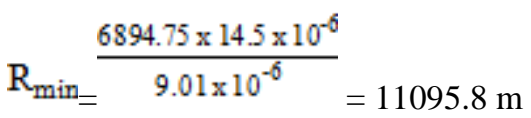

The minimum radius is calculated to be $11095.8 \mathrm{~m}$. Billow is defined as the curvature of the conic section. To carry the payload, 5 CubeSats are considered. A CubeSat is a type of miniaturized satellite which is commonly used in space research and is made up of multiple cubic modules of $10 \mathrm{~cm} \times 10 \mathrm{~cm} \times 10 \mathrm{~cm}$ size.

Table 1. Geometric Specifications

\begin{tabular}{|l|l|}
\hline Sail Dimensions & $150 \mathrm{~m} \times 150 \mathrm{~m}$ \\
\hline Catenary sag & $7.5 \mathrm{~m}$ \\
\hline
\end{tabular}




\begin{tabular}{|l|l|}
\hline Sail thickness & $14 \times 10^{-6} \mathrm{~m}$ \\
\hline Billow (sag) & $0.26 \mathrm{~m}$ \\
\hline Boom Length & $106 \mathrm{~m}$ \\
\hline No. of CubeSats & 5 \\
\hline Dimensions of 1 CubeSat & $10 \mathrm{~cm} \mathrm{x} 10 \mathrm{~cm} \mathrm{x} 10 \mathrm{~cm}$ \\
\hline
\end{tabular}

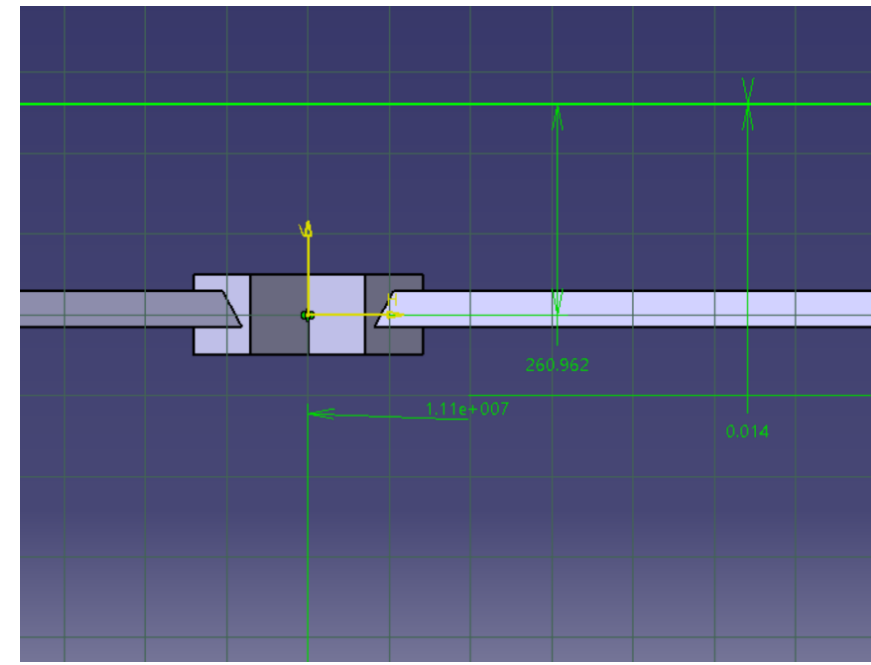

Figure 6. Radius of Curvature, Billow and Sail Thickness

\subsection{Force calculation}

The intensity of the solar radiation is found using the following formula,

$\mathrm{I}=\frac{\text { Avg solar power of the sum }}{4 \pi \mathrm{x} \text { (distance from the sun) })^{2}} \mathrm{~W} / \mathrm{m}^{2}$

The average solar power of the sun at a distance of $1 \mathrm{AU}$ (Astronomical unit) is $3.8 \times 10^{26} \mathrm{~W}$. By substituting the values in the formula,

$I=\frac{3.8 \times 10^{26}}{4 \pi \times\left(1.496 \times 10^{11}\right)^{2}}=1351.172 \mathrm{~W} / \mathrm{m}^{2}$

The intensity of solar radiation is $1351.172 \mathrm{~W} / \mathrm{m}^{2}$.

The radiation pressure is given by,

$\mathrm{P}=\frac{\mathrm{xxI}}{\mathrm{c}}$

where, ${ }^{x}=1$ for opaque, 2 for reflective,

$\mathrm{I}=$ intensity of solar radiation, $\mathrm{W} / \mathrm{m}^{2}$

$\mathrm{c}=$ speed of light $=3 \times 10^{8} \mathrm{~m} / \mathrm{s}^{2}$

By substituting the values in the formula,
$\mathrm{P}=\frac{2 \times 13511 / 2}{3 \times 10^{8}}=9.01 \mathrm{x}^{10^{-6}} \mathrm{~N}^{2}$

The radiation pressure is $9.01 \mathrm{x}^{10^{-6}} \mathrm{~N} / \mathrm{m}^{2}$. Force acting on the sail,

$\mathrm{F}=\mathrm{P} \times \mathrm{A}$

where, $\mathrm{P}=$ Radiation pressure,

$A=$ Area of sail

$\mathrm{F}=9.01 \times 10^{-6} \times 150 \times 150=0.203 \mathrm{~N}$

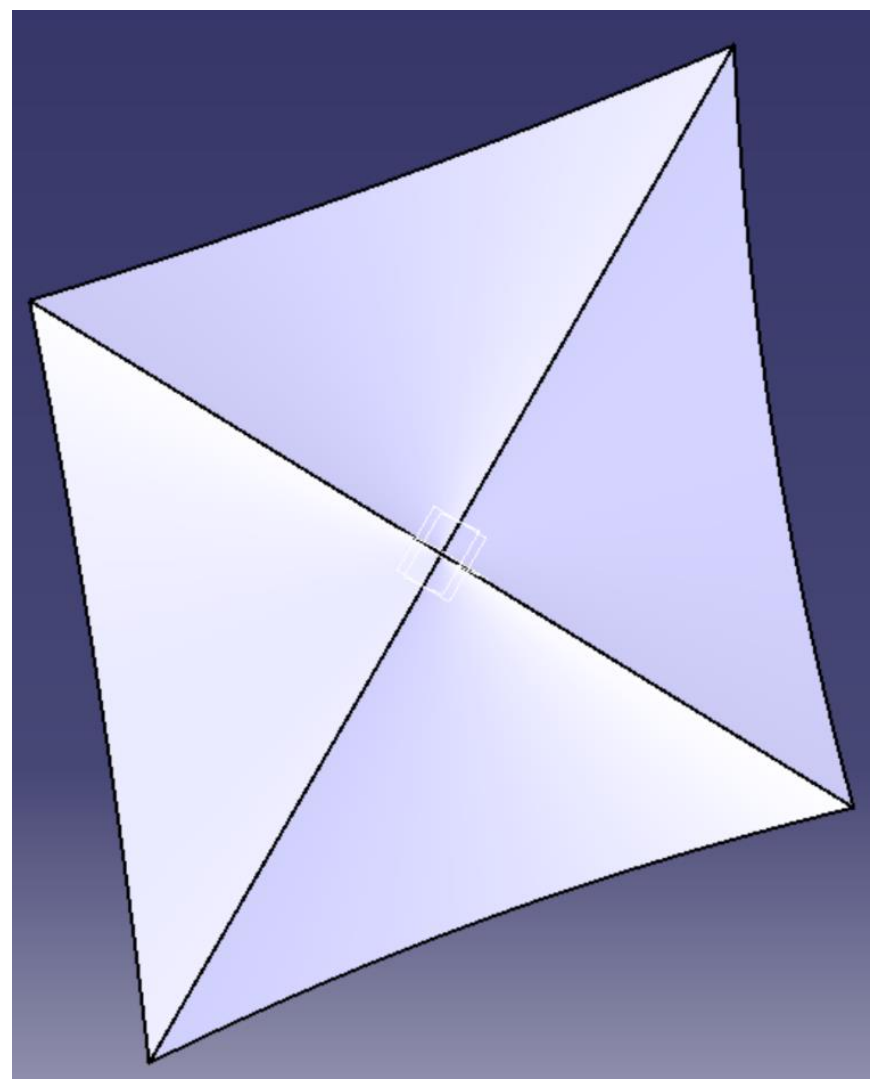

Figure 7. Final Sail Design

\section{Material Selection}

\subsection{Material selection of the boom}

The IKAROS Solar Sail and the Nano Sail both use aluminum as the material for the boom. Many developments and prototypes which is still under Research phase use carbon fiber and M5 fiber as the material due to their high strength and light weight. Since the mission is interstellar space exploration a light weight material having high tensile strength needs to be selected. M5 fiber has higher tensile strength when compared to aluminum and carbon fiber. The density of M5 fiber is lesser when compared to aluminum and carbon fiber. M5 fiber also is less brittle. when compared to carbon fiber. Using M5 Fiber up to $63 \%$ reduction in weight can be achieved. M5 fiber is light weight and also has high tensile strength, Hence 
M5 fiber is selected as the material of the boom because of its high tensile strength and light weight. M5 fiber's composition is based on a rigid polymer dihydroxy phenylene, in comparison to carbon fiber which uses polyacrylonitrile polymer. Dihydroxy phenylene is a high-performance fiber which has higher tensile strength, operating temperature, heat resistance in comparison to polyacrylonitrile.

Table 2. Material Selection of the boom

\begin{tabular}{|l|l|l|l|}
\hline & M5 Fiber & Aluminum & $\begin{array}{l}\text { Carbon } \\
\text { Fiber }\end{array}$ \\
\hline $\begin{array}{l}\text { Ultimate Tensile } \\
\text { Strength (GPa) }\end{array}$ & 3.9 & .690 & 3.8 \\
\hline Density $\left(\mathrm{kg} / \mathrm{m}^{3}\right)$ & 1700 & 2700 & 1930 \\
\hline $\begin{array}{l}\text { Young's } \\
\text { Modulus (GPa) }\end{array}$ & 271 & 68 & 227 \\
\hline $\begin{array}{l}\text { Failure Strain } \\
(\%)\end{array}$ & 2.5 & 0.25 & 1.76 \\
\hline
\end{tabular}

\subsection{Material Selection of the sail}

Mylar is a polyester film that has high reflectivity and is the most common material used in solar sails due to its high reflectivity and high temperature resistance. Mylar has a density of $1.39 \mathrm{~g} / \mathrm{cm}^{3}$ with a Poisson's ratio of 0.38 . It has a young's modulus of $6.3 \mathrm{GPa}$. The thickness is taken as 16 microns which is the standard thickness used in solar sail missions.

\section{Boom configuration selection}

Three shapes are taken into consideration, hollow circular, flat plate and L-shaped. By performing static structural analysis on ANSYS we found out that hollow circular has the least deflection and flat plate has the most deflection. Since the weight of the spacecraft will increase drastically if hollow circular was used, we decided to go with L-shaped boom which has low deflection and also is light weight.

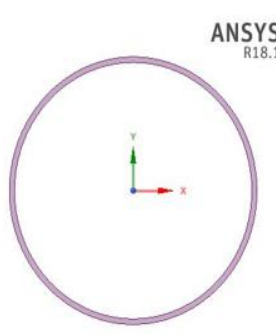

(a) (b)

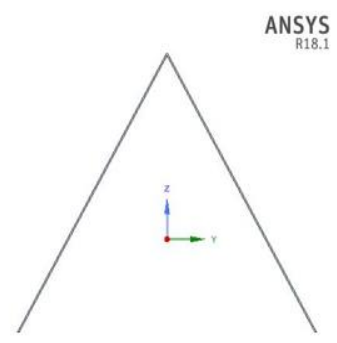

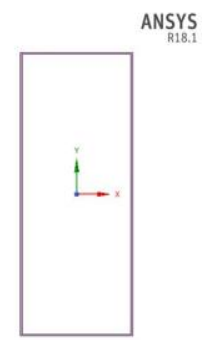

(c)
Figure 8. Final Sail Design

The Rectangular Boom has a cross-sectional dimension of $70 \mathrm{~mm} \times 30 \mathrm{~mm}$. The circular Boom has a cross-sectional dimension of $60 \mathrm{~mm}$ diameter and $0.25 \mathrm{~mm}$ thickness. The $\mathrm{L}$ Shaped Boom has a cross-sectional dimension of $45 \mathrm{~mm}$ height and $0.25 \mathrm{~mm}$ thickness and is modelled with an angle of $60^{\circ}$.

\subsection{Analysis}

In engineering data M5 Fiber is added as the material. In meshing, a tetrahedral mesh is done for the geometry as it fits well for the boom configuration. The rectangular boom structure has 25561 Nodes and 4200 elements. The L Shaped boom has 30973 nodes and 4200 elements. The circular boom structure has 85655 nodes and 19392 elements. In Static Structural Analysis, the boundary conditions are defined. Fixed support is added at one end and a uniform force of $0.5 \mathrm{~N}$ is added to measure the amount of deflection caused in the three boom configuration cases. From force calculations, force acting on the solar sail is $0.203 \mathrm{~N}$. Considering Safety factor, we have taken $0.5 \mathrm{~N}$.

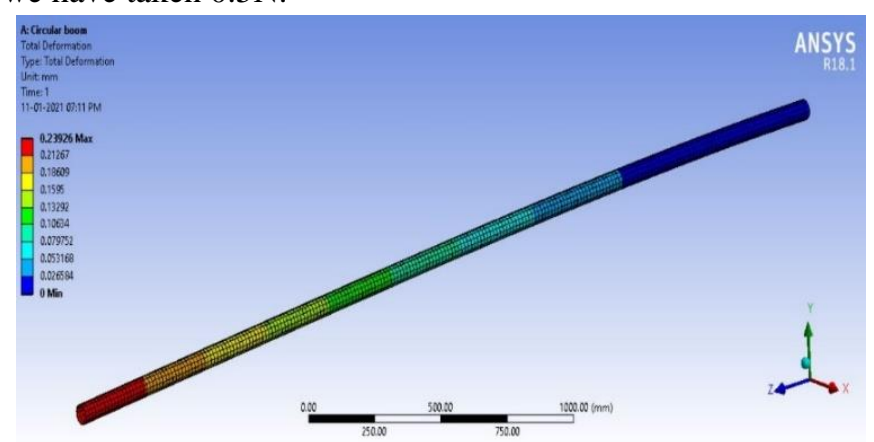

Figure 8. Hollow Circular Boom Analysis 


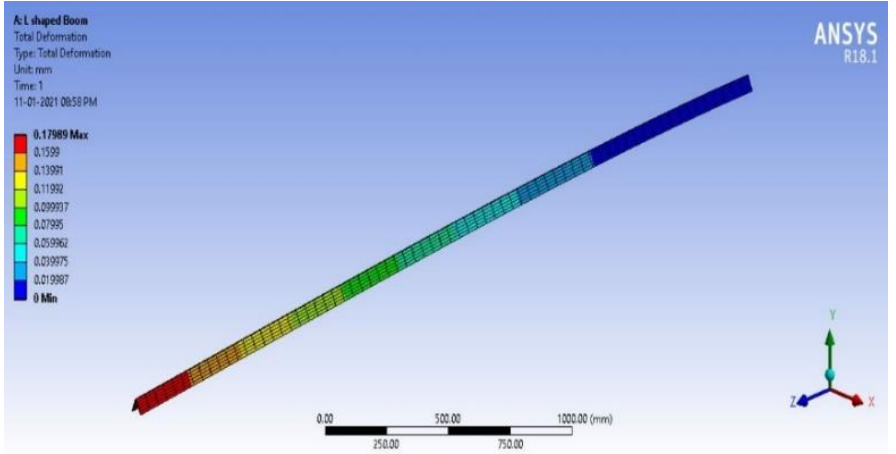

Figure 9. L-Shaped Boom Analysis

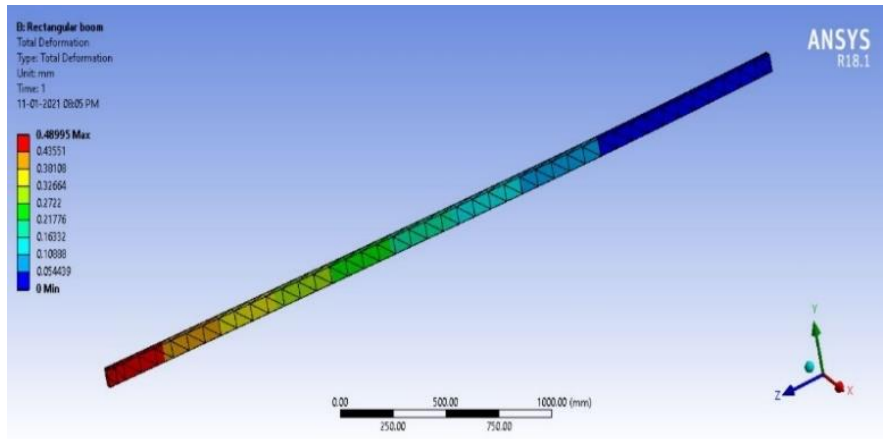

Figure 10. Rectangular Boom Analysis

Table 3. Boom Deflection

\begin{tabular}{|l|l|l|}
\hline Configuration & Deflection(mm) & $\begin{array}{l}\text { Mesh } \\
\text { Elements }\end{array}$ \\
\hline Hollow Circular & 0.239 & 189582 \\
\hline L-Shaped & 0.179 & 40973 \\
\hline Rectangular & 0.489 & 25561 \\
\hline
\end{tabular}

\section{Grid Independence Test}

Grid independence study is performed to reduce the influence of the grid size on the computational results. The element size is varied from $40 \mathrm{~mm}$ to $5 \mathrm{~mm}$. It is found at from $25 \mathrm{~mm}$ element size the deflection value remains almost constant.

Hence an element size of $5 \mathrm{~mm}$ is taken during meshing. From Fig 11 the deflection v/s number of mesh elements graph for the rectangular boom, from 10000 mesh elements the value for deflection remains almost constant.

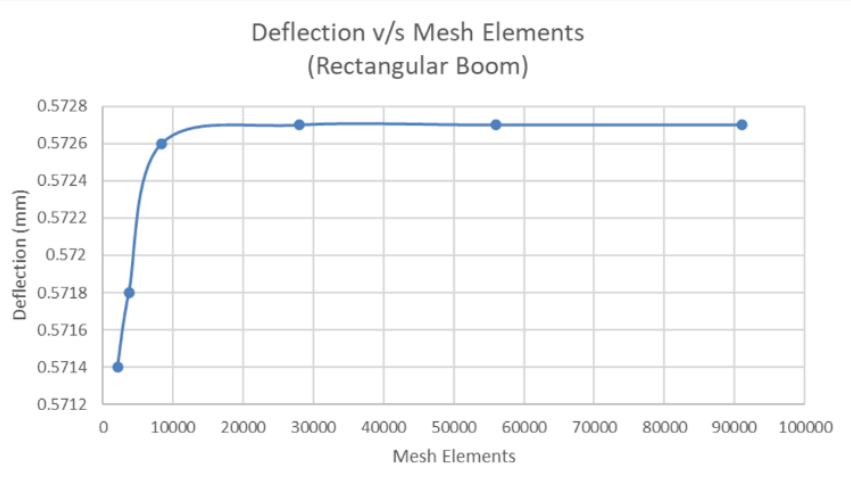

Figure 12. Rectangular Boom

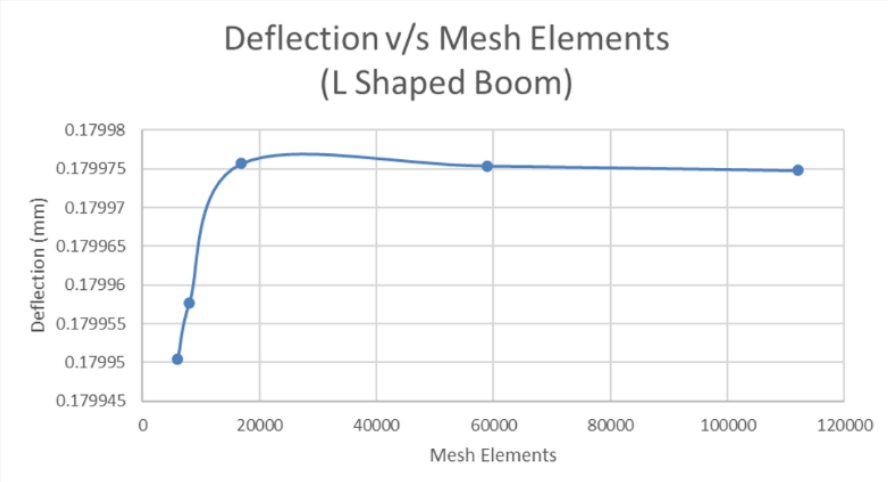

Figure 13. L-Shaped Boom

From Fig 12 the deflection v/s number of mesh elements graph for the L shaped boom, from 40000 mesh elements the value for deflection remains almost constant. From Fig 13 the deflection v/s number of mesh elements graph for the hollow circular boom, it can be seen that from 2,00,000 mesh elements the value for deflection remains almost constant.

\subsection{Conclusion}

A theoretical sail design is developed under the ideal conditions. The continuous connection configuration is ideal to implement any new mechanism or improvements to the sail. The selected L-shaped boom configuration has advantages over the conventional configurations both in terms of weight and strength. The design was optimized for maximum acceleration, with an intention of an interstellar mission. Since it is a superstructure, materials were selected based on the most optimum material available to us, until advanced materials are developed or invented for space structures and advances in engineering, manufacturing and physical technology are required. Force considered are calculated based on the sun at orbital level of earth. The designed solar sail can be further developed to add new innovative improvements that will enhance the overall performance and reliability of the solar sail. The deployment system of the sail system had to be developed. Boom retraction mechanism can be engineered. Maneuverability of the sail can be developed. The innovations in the field of solar sail propulsion are boundless. For any further work, the assumptions and conditions are to be taken care of accordingly considering the limitations of this paper.

\section{References}

[1] Girolamo Costanza., Gabriele Leoncini., Fabrizio Quadrini., Maria Elisa Tata., Design and Characterization of a Small-Scale Solar Sail Prototype by Integrating NiTi SMA and Carbon Fibre Composite. Dipartimento di Ingegneria Industriale, 2017

[2] Luisa Boni,, Giovanni Mengali., Alessandro A Quarta., Solar sail structural analysis via improved finite element modeling. . Journal of Aerospace 
Engineering, 2016.

[3] J. fan., J. Njuguna., An introduction to lightweight composite materials and their use in transport structures..SKF Engineering Research Center, 2016.

[4] Soufen, Carlos A., Campos, Marcelo C., Imaizumi, Momotaro., Study of the mechanical properties of composite laminated with kevlar in comparison with those of carbon fiber..Brazilian conference on composite materials, 2014.

[5] Les Johnson., Roy Young., Edward Montgomery., Dean Alhorn., Status of solar sail technology within NASA..Elsevire Ltd. On behalf of COSPAR publication, 2010.

[6] David Holland., Lawrie Virgin., Experimental Modal Analysis of Solar sail Booms. 49th AIAA Structures, Structural Dynamics and Materials Conference, 2008.

[7] Alexander Bolonkin., High Speed AB-Solar Sail. 42nd AIAA Joint Propulsion Conference, Sacramento, 2006.

[8] Kamaldeen Yusuff., Mohammad Mahinfalah., Amin Salehi - Khojin., Mohammad Alimi., Low velocity imapact of carbon/zylon and carbon/kevlar composite laminates. ASME International Mechanical Engineering Congress and Exposition, 2005.

[9] G. Greschik., M. Mikulas., Design Study of a Square Solar Sail Architecture. 42nd AIAA Joint Propulsion Conference, Sacramento, 2002.

[10] Philip M. Cunniff., Margaret A. Auerbach., Eugene Vetter., High performance "M5" fiber for ballistics / structural composites. 42nd AIAA Joint Propulsion Conference, Sacramento, 1999. 